Indian Journal of Science and Technology

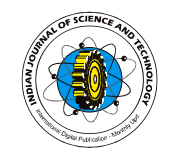

\title{
Biological synthesis of silver nanoparticles by Aspergillus flavus, isolated from soil of Ahar copper mine
}

\author{
Saeed Moharrer*, Behroz Mohammadi, Reza Azizi Gharamohammadi and Mehdi Yargoli \\ Department of Microbiology, Zanjan Branch, Islamic Azad University, Zanjan, Iran \\ *moharrer_934@yahoo.com
}

\begin{abstract}
In this study, silver nanoparticles were synthesized using the fungus, Aspergillus flavus at high yield with an aqueous solution of $\mathrm{AgNo}_{3}$. The formation of silver nanoparticles was confirmed using UV-visible spectrophotometer and their presence was displayed by XRD studies. The size and place formation of silver nanoparticles were investigated using Scanning Electron Microscopy (SEM).
\end{abstract}

Keywords: Silver nanoparticles, Fungi, Aspergillus flavus, Biosynthesis.

\section{Introduction}

Nanotechnology involves the production manipulation and use of materials ranging in size from less than a micron to that of individual atoms (Badri Narayanan \& Natarajan, 2010; Gajendran, 2007). One of the most important criteria of nanotechnology is that of the development of clean, nontoxic and eco friendly green chemistry procedures (Sharma \& Yangard, 2009). Silver nano particles have found potential application in many fields such as, antibacterial effect, biological sensors, drug delivery, textile, and filters (Elechiguerra et al., 2005; Gajendran, 2007). Nanoparticles can be synthesized by physical, chemical and biological methods (Kathiresan, 2009). Synthesis of nanoparticles employing microorganisms has attracted much due to their usual optical, chemical, photoelectron chemical and electronic properties and many biological organisms, such as bacteria, fungus, yeasts and plants either intra or extracellular (Castro-Longoria et al., 2010) which are of higher production yields and with low expenses. Fungi are ideal candidates in the synthesis of metal nanoparticles, because of their ability to secrete large amount of enzymes (Kathiresan et al., 2009). In this regard, we report the use a fungi Aspergillus flavas in synthesis of extra cellular of silver nanoparticles.

\section{Material and methods}

All chemical agents including $\mathrm{AgNo}_{3}$ were prepared from sigma. The Aspergillus flavus fungus isolated from Ahar (Iran) copper mine soli and was cultured in SDA slant. Soil sample was remained in $4^{\circ} \mathrm{C}$ for next experiments. One gram of soil sample was serially diluted in sterilized distilled water to get a concentration range from $10^{-1}$ to $10^{-6}$. A volume of $0 / 1 \mathrm{ml}$ of each dilution was transferred aseptically to plates. Then fungus growth after $48 \mathrm{~h}$. any one of fungus was cultured in new SAD plates until perfect isolation of fungus. Then $A$. flavus was isolated by slide culture method for examination. For syntheses of silver nanoparticles from the biomass, Aspergillus flavus was growth in $250 \mathrm{ml}$ Erlenmeyer flask containing $100 \mathrm{ml}$ MYPG medium which composed of malt extract $(3 \mathrm{gr} / \mathrm{L})$ peptone $(5 \mathrm{gr} / \mathrm{L})$, glucose $(10 \mathrm{gr} / \mathrm{L})$ and yeast extract (3gr/L) (Ahmad et al., 2003). This culture was incubated on orbital shaker with 150-rpm agitation at $28^{\circ} \mathrm{C}$ for $96 \mathrm{~h}$. After $96 \mathrm{~h}$ incubation, fungal biomass was Separated from MYPG broth by centrifuge $3500 \mathrm{rpm}$ at $10^{\circ} \mathrm{C}$ for 20 minutes and washed with distilled water to remove any medium components. Fresh and clean biomass was exposed in $100 \mathrm{ml}$ of $1 \mathrm{Mm}$ aqueous $\mathrm{AgNo}_{3}$ solution by pH 6.5 in $250 \mathrm{ml}$ Erlenmeyer flask. The whole mixture was put into a shaker at $28{ }^{\circ} \mathrm{C}$ for $72 \mathrm{~h}$ in dark. The sample was scanned in the range of 350 to 750 by UV-visible spectrophotometer (Bhainsa \& D'Souza, 2006). Sample was powdered and prepared for X-Ray diffraction at the end step. Sample was fixated by glutaraldehyde, dehydrated by alcohol for SEM analysis (Vigneshwaran et al., 2007; Talebia et al., 2010).

Fig. 1. Change of biomass color from colorless (Right) to brownish (Left)

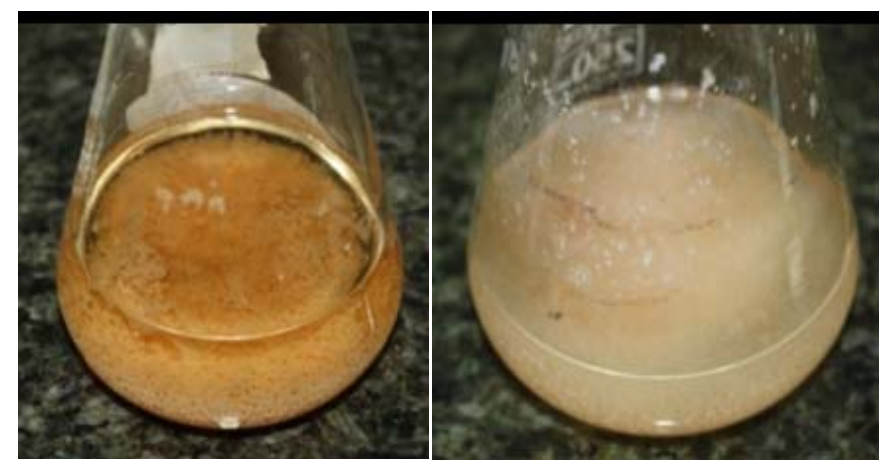

\section{Result and discussion}

The biomass that mixing with the aqueous solution of $\mathrm{Ag}$ ions, the color of the biomass changed from colorless to brownish (Fig.1) usually after 72 incubation that was the first symptom of nanosilver production. UV-Visible spectrophotometer results showed a peak at $425 \mathrm{~nm}$ (Fig. 2). X-RD pattern was compared with standard pattern and evidenced for production of nanosilver crystals (Fig.3). In final step, prepared a SEM picture and showed silver nanoparticles in size rang $7 \mathrm{~nm}$ (Fig. 4). In earlier 
research, production of silver nanoparticles in fungi with a number of these particles trapped on the mycelia (Mukherjee et al., 2001). Our results then showed similar silver nanoparticles that were involved on the mycelia and not found in solution. This may be caused by electrostatic reaction among $\mathrm{Ag}^{+}$of $\mathrm{AgNo}_{3}$ and groups with negative

Fig. 2. UV-visible spectrophotometer scans in the range of 350 to 750

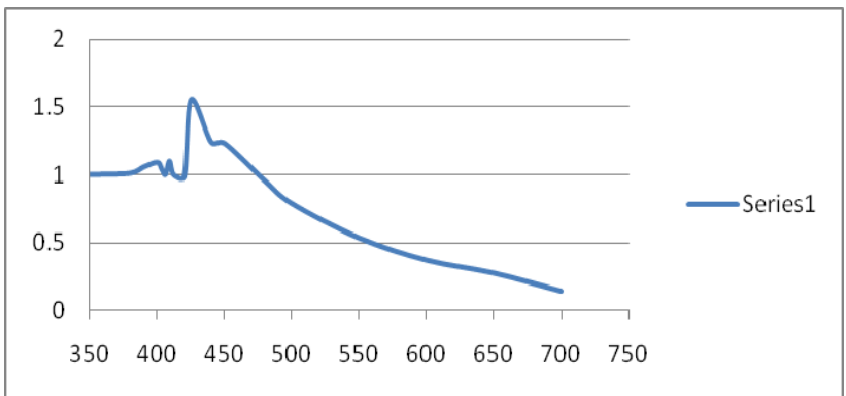

Fig. 3. X-Ray diffraction of fungi powder
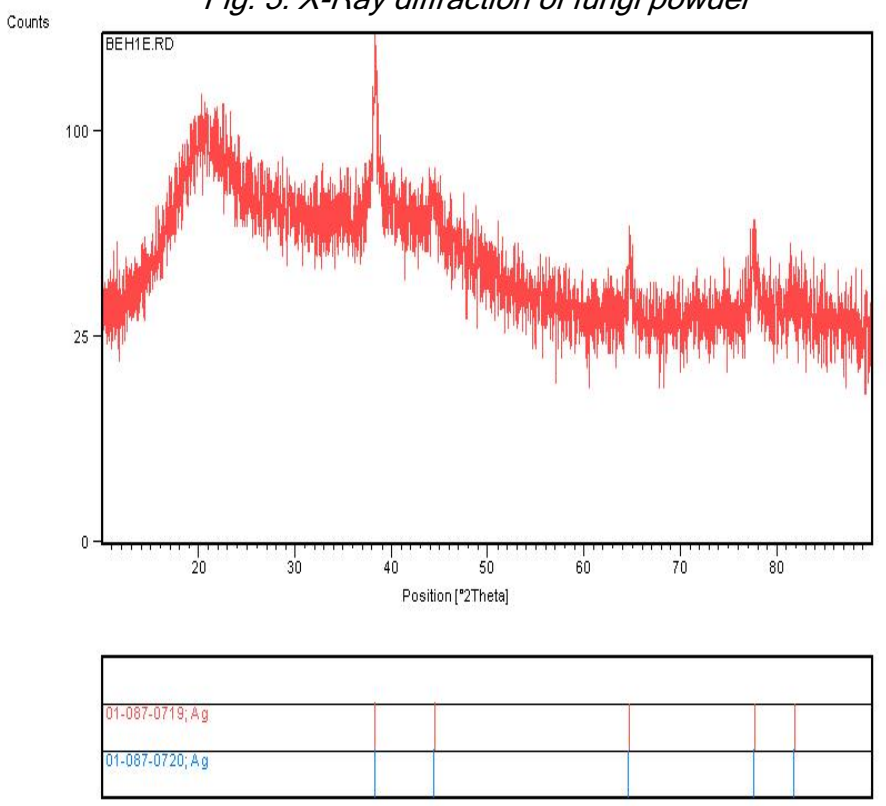

Fig. 4. SEM picture of silver nanoparticles in the Aspergillus flavus

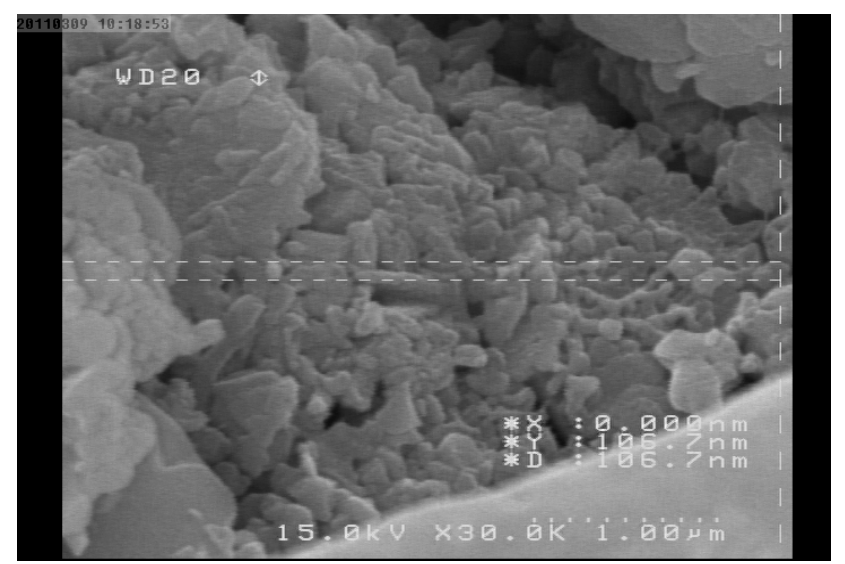

Vol. 5 No. S3 (Mar 2012)

ISSN: 0974- 6846

charged (carboxylate groups) in enzyme present in the cell wall of the mycelia.

Conclusion

A green chemistry synthetic route has been used for silver nanoparticles. Microorganisms have been employed for syntheses of metallic nanoparticles. In next investigation we can used fungi that isolated from metallic mines for synthesis of other metallic nanoparticles, as the microorganisms are resistant to metallic stresses.

\section{References}

1. Ahmad A, Mukherjee P, Senapati S, Mandal D, Khan MI, Kumar R and Sastry M (2003) Extracellular biosynthesis of silver nanoparticles using the fungus Fusarium oxysporum. Colloids Surf B. 28, 313-8.

2. Badri Narayanan K and Natarajan S (2010) Biological synthesis of metal nanoparticles by microbes. Adv. Colloid Interface Sci. 156, 1-13.

3. Bhainsa, KC and D'Souza, SF (2006) Extracellular biosynthesis of silver nanoparticle using the fungus Aspergillus fumigates. Colloids Surf B, Biointerfaces, 47, 160-4.

4. Castro-Longoria E, Vilchis-Nestor $A R$ and AvalosBorja M (2010) Biosynthesis of silver, gold and bimetallic nanoparticles using the filamentous fungus Neurospora crassa. Colloids Surf. B Biointerfaces. 23,112-117.

5. Elechiguerra J, Burt J and Morones JR (2005) Interaction of silver nanoparticles with HIV-I. J. Nanobiotechnol. 3, 6.

6. Gajendran N (2007) Adding Life to the nanotechnology. Indian J.Sci.Technol. 1 (1), $1-5$. Retrieved May 28, 2011, from http://www.indjst.org.

7. Gajendran N (2007) Adding Life to the nanotechnology. Indian J.Sci. Technol. 1 (1), 1-5.

8. Kathiresan K, Manivannan S, Nabeel MA and Dhivya B (2009) Studies on silver nanoparticles synthesized by a marine fungus, Penicillium fellutanum isolated from coastal mangrove sediment. Colloids Surf. $B$ Biointerfaces, 71, 133-137.

9. Mukherjee P, Ahmad A, Mandal D, Senapati S, Sainkar SR and Khan MI (2001) Fungus mediated synthesis of silver nanoparticles and their immobilization in the mycelial matrix: a novel biological approach to nanoparticle synthesis. Nano Lett. 1, 515-9.

10. Sharma VK and Yangard RA (2009) Green synthesis and their antimicrobial activities. J. Colloid Interface Sci. 9, 83-96.

11. Talebia S, Ramezanib F and Ramezani M (2010) Biosynthesis of metal nanoparticles by microorganisms. Nonocon. 10,112-118.

12. Vigneshwaran N, Ashtaputre NM, Varadarajan PV, Nachane RP, Paralikar KM and Balasubramanyaet $\mathrm{RH}$ (2007) Biological Synthesis of silver nanoparticles using the fungus Aspergillus flavus. J. Mater. Lett. 67, 1413-1418. 